\title{
Axiological Analysis of Intergenerational Relations in a Globalized Society: Myth and Reality
}

\author{
Svetlana L. Shalaeva ${ }^{1} \&$ Anastasia V. Shalaeva $^{2}$ \\ ${ }^{1}$ Mari State University, Yoshkar-Ola, Russia \\ ${ }^{2}$ National Research University Higher School of Economics (HSE), Moscow, Russia \\ Correspondence: Svetlana L. Shalaeva, Institute for Pedagogy and Psychology, Mari State University, Lenin \\ Square 1, 420000, Yoshkar-Ola, Russia. Tel: 7-836-245-5618. E-mail: svet_0864@mail.ru
}

\author{
Received: February 21, 2015 Accepted: March 15, 2015 Online Published: April 29, 2015 \\ doi:10.5539/res.v7n8p246 URL: http://dx.doi.org/10.5539/res.v7n8p246
}

\begin{abstract}
This article examines the phenomenon of intergenerational relations in contemporary society. The model of intergenerational relations is the basic model of individuals' social behavior, generations' relationship and other social communities; it influences the social dynamics in general. The research explores the growing crisis of these relations and social metamorphoses caused by the nowadays society's dynamic changes. These changes are associated primarily with the transformation of the contemporary person's values and worldview with the advent and development of the new media. The analysis of the changes suggests the prefigurative nature of contemporary culture, as evidenced by recent studies of mimetic and ritual behavior of today's children. The article discusses the phenomenon of Indigo children, as a particular confirmation of the crisis of intergenerational relations.
\end{abstract}

Keywords: the world of childhood, the world of adults, prefigurative culture, new media, mimesis, mythological consciousness

\section{Introduction}

Contemporary scholarschip shows dramatically growing interest in the study of the phenomenon of childhood. The growth of this interest is not so much due to the understanding of the strategic role of childhood in existence, sustainable development and the future of any society, as due to those rapid transformations that occur with the World of Childhood in a rapidly changing world.

Childhood - is a period of formation of a child a full member of human society, in a general understanding, a period from birth to the complete social maturity, which in Russian society means 18 years old. In other words, childhood is a time of individual's intensive development, which is impossible without the intermediary role of the adult. An adult is a mediator between the child and the sum of social and cultural values, attitudes, norms that defines the conditions of life in a given society and the ability to normally live in it. From this perspective, the relationship of adults and children may be called a dyad, a psychological symbiosis, as it is-a holistic system, a form of organization of joint life and activities, which provides mutual process of socialization for both parties.

"Russian psychologists repeatedly documented the existence of this kind of psychological symbiosis. Thus, Vygotsky (1984) suggested a holistic system of interaction "child-adult", Daniil B. Elkonin (Elkonin, 1978) — a system "children and society" ("children in society"), Kudryavtsev (2001) - a commonality of "child-adult" as an active "polisubject of development" or "subject of culture".

From the point of view of social philosophy, any society can be roughly described as a dialectical unity of two complementary social structures - the World of Adults and the World of Childhood. Both worlds play an equally important role in ontogenetic and phylogenetic scope of human history, and their relations have always been the unity and struggle. These two worlds are mutually beneficial: they could not exist without each other; they help each other in the socialization process of providing inheritance, transferring social and historical memory, which produces society as an integral structure. At the same time, though they negate each other. This negation is inherent from the outset of their opposition, which Elkonin believes to take place due to the complexity of content and forms of employment rights (primarily-instruments of labor). The negation appeared when the children were not immediately included in the adult life so the childhood has become a special period of life, 
necessary for general orientation in a complex world of organized human activity.

An extensive body of contemporary literature indicates conflicts and crises increase of this relationship.

\section{Results}

The problem of the generations' relationship, the "fathers and sons" problem has always existed, but today it increases and accepts transformed forms. The complexity and contradictions of these relationships in contemporary society is beginning to be realized and referred to as a "crisis of childhood" (Elkonin, 1992), "a unique social situation of development of modern childhood" (Abramenkova, 2000), "technologization of the World of Childhood" (Shalaeva, 2009b), and so on. The growth of adults and children relationship crisis is largely explained due to the rapid social changes that we are witnessing today.

\subsection{Personality and/or Sociality}

Contemporary society is rapidly changing, it sociocultural environment undertakes ontological and axiological shocks that affect the principles of humanity and interpersonal relations. In the new situation of social development conservative beliefs, ideas represented by the strong state, centralized power, strengthening and supporting families, the inviolability of of moral principles, protection and conservation of traditional spiritual values are replaced by liberal values and ideas, based on the anthropological doctrine of an individual.

Meanwhile, throughout the ages a human being sought to establish himself both as a person and as a social being. These spheres of personality approval are inextricably linked. It is the harmony of the social and the individual that provides the harmonious development of personality and society.

Today this historical development model tilts toward individualism, raised based on the Western culture. The Western researchers document this metamorphosis. Thus, a contemporary French philosopher Alain de Benoist (Benoist, 2009) underlines that in the long-term global progress, starting from the 18 century, the emancipation of the individual from his public relations was interpreted as an achievement of "adult age" society. According to the author, the liberal idea proved to be an economic doctrine that seeks to produce a self-regulating market model for all social facts. Today, the social sphere is also becoming a factor of production and consumption, herein everything is governed by supply and demand, market value, and the fact that cannot be numbered and measured is easily overlooked. Social phenomena are gradually reduced to the "universe of measurable things" (Benoist, 2009). Thus, we can speak of social and human knowledge and practice technologization as of a of a society system technologization manifestation.

Today the liberal individual doctrine and marketing strategy in the personality's social efficiency assessment lead to significant changes in the functioning of social institutions (family, morality, education, upbringing).

\subsection{New Media, Ritual, Mimesis}

During the crisis of the family and child community disintegration the means of mass media play the main part in the social institutions ranking. Media actively invade to the intimate world of the individual and promote mass patterns of the way of living, secure art- or any type of world's consumption in the form of things for a person (Shalaev, 2013). Mass media has a distinctive part in formation of mass consciousness, manipulating it, causing myths and illusions, simulacra-all which is defined as "false consciousness" and received boost to the development in the postmodern era (Papanis, Giavrimis, \& Papani, 2010).

Under these circumstances, the transfer of sociocultural experience is no longer on behalf of the older generation to the younger, "from hand to hand". It is mediated by a medium, for instance, the information environment, primarily through the screen (cf. Willis, 1999). Development of the new media caused another wave of interest in the study of ritual within the social sciences and humanities. The study is based on the premise that many types of interactions in society are planned and performed as rituals, or complex social processes that vary in purpose, content and context (Wulf et al., 2010). Rituals create social cohesion and help groups and societies to overcome internal problems and resolve conflicts. Organization and participation in rituals give the opportunity to overcome existing differences and give stimulus to the production of cultural communities. According to recent ritual studies within the framework of historical anthropology, children produce their social life by arranging themselves and their relationships in the rituals. However, children learn to learn, behave and live in the ritual actions namely (Delors, 1996). Thus a special area of study of childhood and adulthood rituals is allocated.

In contrast to the verbal forms of communication, rituals - are the social constellations where individual and community social actions together with the methods of interpretation produce structures and hierarchies (McLaren, 1993; Alexander, Anderson, \& Galegos, 2004). Rituals include both traditional rituals: celebrations, 
ceremonies, religious events, initiation (in cases of birth, marriage, death); and a variety of daily rituals. One of the central notions here, along with the notions of gesture and ritual, is the concept of mimesis. Mimesis as an inherent human ability to imitate is regarded as the concept of anthropology as a specific creative imitation in the performative representation (Wulf, 2001). In this regard, we cannot deny a significant impact of the new media (television, internet, and digital media) on daily ritual processes of communities' production in the children's culture. Thus, the ritual practical knowledge is acquired through mimetic training in the performance of ritual acts (cf. Willis, 1999; Wulf et al., 2010).

Children reflect, repeat and reproduce a general atmosphere of global consumerist civilization that is committed to the success of the individual and the cult of corporal over the spiritual. In the education of the younger generation the first part play the values of consumerism, individualism, pragmatism and egoism, the transfer of the sum of knowledge, and all of this dominates the capacity for judgment, altruism, society as a basic value, creativity, traditional morality (cf. Piaget, 1968). Children are increasingly becoming a springboard for the victory of technologism and instrumentalism over the humain and spiritual.

A human being cannot become a person outside of the social. Individualist priorities prevailing on the early stages of child's development in the basic social institutions change their structure, the nature of socialization, and lay imbalances in the developing personality.

These are conditions that explain the present destruction of traditional institutions of socialization and replace them with new, non-classical forms, depriving childhood of harmonious socialization, based on the dialectical equilibrium of the individual and the social in the person. In the long term, these changes are making the person a convenient object of consciousness mass manipulation in a global society. Real statistical confirmation exists for reducing children number in the community; the growing number of divorces and single-parent families; the rapid growth in the number of unregistered marriages where the divorce rate is even higher; growth of childless families; the ideas of conscientious objection to parenthood; reducing time and deterioration of children-parents communication quality; an increase in violence in the family (Shalaeva, 2009a).

The reasons that we have noted explain the changing relationship between the World of Adults and the World of Children and indicate the presence and some causes of children and parents alienation.

\subsection{Prefigurative Culture}

It was 1988 when the first Russian translation appeared of the book Culture and Commitment: A Study of the Generation Gap by Margaret Mead - an American anthropologist, student of Franz Boas. She was the first ethnographer, for whom the world of childhood has become a major and primarily subject of study. Conducting field work on the islands of Oceania, she gathered vast amount of material on children socialization in primitive cultures. After analyzing the features of socialization of the younger generation in primitive cultures and in a civilized society, she created a theory on the specifics of intergenerational interaction and identified three cultures types in human history in terms of the nature of experience translation between generations:

1) Postfigurative culture - children learn from their ancestors. So, in a patriarchal society based on tradition and its living bearers, the elderly, the relationship of age groups are strictly regulated, innovations are not approved, everyone knows their place, dominated by a sense of continuity and loyalty to tradition.

Postfigurative cultures are oriented towards the past.

2) Cofigurative culture - children and adults learn from equal, ie, their peers. The influence of older decreases. The extended family is replaced by nuclear, firmness of traditions is shaken. The significance of youth groups grows they present a particular subculture.

Cofigurative cultures are oriented towards the present and the moderate pace of progress.

3) Prefigurative culture - adults learn from their children. Such a culture emerged since the mid $20^{\text {th }}$ century and is united within electronic communication network. They define a new type of social bond between generations, a way of life of the older generation does not gravitate the younger. Rate of knowledge renewal is so high that young people are more conversant than the elderly. Exacerbated by intergenerational conflicts, youth culture develops into a counterculture.

Prefigurative cultures are oriented towards the future and accelerated movement. Life in a prefigurative culture encourages people to develop individual and creative activity capable of focusing on the future to predict, to dream, to flexibly move to the new activities, even in situations of uncertainty.

In the mid $20^{\text {th }}$ century it was hard to believe in the possibility of the prefigurative culture arrival. Now the words written by Margaret Mead in the 60 -ies of the $20^{\text {th }}$ century are striking with the genius of foresight. She insists 
that today, all of a sudden, in all parts of the world where all peoples are united in electronic communication network, young people gathered in a common experience, the experience that their parents will never obtain. On the contrary, the older generation will never see how their experience of unprecedented change repeats in the lives of young people. This generation gap is brand new, it is global and universal. Contemporary children grow up in a world that is not familiar to their parents, but some of the adults anticipated that that would happen. Those who foresaw were proved to be the harbingers of the future prefigurative culture with the upcoming unknown (Mead, 1988).

An analysis of contemporary social change in the relations between generations allows establishing a clear advance of a prefigurative culture. Due to the higher adaptive capacity of children, the children's credibility significantly increases in the eyes of their parents. For their parents children are the role models of the new styles of behavior: what type of home appliances and where to buy, what to wear, how to communicate, how to work on your computer. In some knowledge and skills, children are aware of their superiority over the parents, so in their eyes of children their parents lose the right to guide and evaluate their behavior.

Children and adults are thus involved in the process of mutual constructing and carry out mutual support, as well as produce risks. Mutual penetration of childhood and the adult world leads to the phenomenon of acceleration of childhood and adulthood infantilization.

\subsection{Childhood as a Role Model}

As an example of the childhood metamorphosis in a globalized and postmodern world is a legitimately positioned "inner child" in an adult, combining the "childishness" and "adulthood" not only interpersonally, but also individually. Gradually adulthood ceases to be a value and even more than that children's psychological characteristics, images, behaviors and creativity (spontaneity, emotionality, "childishness" in crafts etc.) increasingly penetrate into the adult world (phenomenon gamification, Peter Pan syndrome, Feldenkrais movement technique et al.). We may ascertain the growing influence of leisure activities and recreation among the youth, as well as extreme sports in the adult world (cf. Valkanos, Giossi \& Anastasiadou, 2010; Panitsidou \& Papastamatis, 2009).

According to Goralik (2008), the emergence of the "new adults" is evidence of a gradual change in the life cycle, arising from the "new childhood" and rolling in the "new aging" associated with changes in values, lifestyles and labor strategies. Goralik emphasizes that the phenomenon of "new adults" is a natural consequence of the "new childhood", quite secure, devoid of physical suffering, relatively independent, applying for rights and privileges. This sense of comfort and security is translated to the distant future, making adjustments in the lifestyle and goal-setting, according to which there is no urgent need for the earliest possible career building, family starting and children as old age protection guarantees.

Liberal ideas in the form of postmodern culture decisively influenced the formation of the phenomenon of prefiguration in modern Russian society. They switched to our culture from the western situation of changes and the destruction of traditional social institutions. Prefiguration, in its essence is a process of metamorphosis, a change in social statuses, social roles of individuals and social groups.

These processes most clearly expressed, for example, in the sphere of relations between the sexes and generations. As the result served the growth of infantilization of the adult world and the loss of their rational worldview control over the world of childhood, close to the state of ideological and social chaos.

\subsection{The Phenomenon of "Indigo Children": Myth or Reality}

In these circumstances, attention is drawn to the phenomenon of "indigo children", which became popular in 1999 after the success of the book by Lee Carroll and his wife Jan Tober The Indigo Children: The New Kids Have Arrived (1999). The conclusion that is in this book - today's children have changed - they are more restless, more developed intellectually, more conflict, more intuitive, more spiritual, and in some cases even more cruel.

Specificity of personal and behavioral characteristics of Indigo children is referred to as asocial, low sociability, a tendency to withdraw into themselves; self-esteem, individualism, reluctance to obey others, rejection of authority; great creativity combined with a high level of intelligence; propensity to acquire knowledge empirically; interest in distant subjects; restlessness, energy, attention deficit; impulsiveness, mood swings and behavior under unfavorable circumstances prone to depression; sense of social injustice, an increased sense of responsibility; immunity to the traditional education techniques; developed intuition and sense of danger; the ability to quickly master the use of digital technologies.

Skeptical Russian teachers, psychologists and journalists have noted that the phenomenon of "indigo children" 
has the character of a hoax. A child psychologist Elena Golubeva said "I would beware talking about indigo children as a scientific phenomenon. For me, it is rather a complex of many factors, including changing with social development educational methods. Today we have changed the social and psychological impact on children so changed the children themselves". Galina Pilyagina, Professor of theNational Medical Academy of Postgraduate Education calls the theory of indigo one of the most colorful modern myths and at the same time the field for a variety of interpretations and believes that all the hype around such children and it is more related to psychology and problems of the parents, not the children. Larissa Gridkovets, Ph. D., says "If, for example, there is the idea of the seventh race, then somebody needs it and the further, the more the story of indigo children is similar to a business project or, more precisely - the development of an ideological infrastructure. Today the entire organizations work on the cultivation of indigo myth, starts advertising and media publications. Such ideological demand exists, firstly, at the expense of customers - in fact, parents who are unable to fully perform their parental obligations. Against the background of parental has been gradually formed and economic order". Doctor of Psychology and Doctor of Education Alexander Savenkov offers to qualify this phenomenon as a very "serious social and psychological pathology that has infected the consciousness of modern Russian philistine" (Savenkov, 2009).

We consider that the term "indigo children" cannot be currently considered as scientifically valid. Rather, the introduction of this term to the discussion of the problems of educating the younger generation and intergenerational relations could be appropriately called an attempt to create and approve in the minds of many people (especially adults) a myth. We must admit that the myth has a "fertile soil". We can distinguish the following reasons that led to the demand for this idea:

1) In fact, today's children have changed; Russian educators, psychologists, school teachers, kindergarten teachers claim that. Independently of foreign researchers in the last two decades in Russia there appeared literature on these children, but without the use of the term "indigo children" (eg, "New Children" by Medvedeva and Shishova).

2) However, it is not only in the fact that at the end of the $20^{\text {th }}$ century there were some unusual children, and that society (teachers, parents, psychologists) have become interested in the phenomenon of childhood, gazing out to the children to notice the child's identity, difference from others. For the domestic interest of the reader, this is amply justified if we recall that for decades the domestic pedagogy and psychology talked about some "average" child of development "age norms", which hinted a bright personality of "nonstandard" children beyond and they did not fit into the existing conventional frameworks and schemes.

3) Rapid social changes lead to a dramatic change in the nature of intergenerational relations, which are characterized by the growth of conflicts, which are increasingly taking the conversion (artificial) forms. These consequences are deformation of the traditional social system of values, a change in the numerical imbalance between older and younger generations, structural and functional aspects of the crisis of the traditional family, a sharp drop in the rating of the family as a social institution.

4) Against the background of the increasing number of children that differ from the norm of development and with a pronounced personality of behavioral characteristics, as well as the growing crisis of the relationship, the recognition of the phenomenon of Indigo children releases from solving set of problems of child development, as well as emerging, proliferating and growing intergenerational challenges . In the easy tone of public talk of these challenges on the phenomenon of Indigo children are manifested the lack of time and effort to understand the problems of a child, and sometimes the adults' unwillingness to impose these burdens on themselves, which confirms the growing parenting dosing, parental selfishness and partly responsibility.

5) One should remember the high degree of mythologizing in the consciousness of the Russian people as one of the most prominent features of the Russian mentality, as Berdyaev detailed in the early 20th century. Numerous illustrations of this idea widely represented in the Russian literature.

Although the reign of the mythological consciousness over the rational is long gone and was overcome by the first Greek philosophers and scientists, mythological model do not completely lose its influence in the modern society. Still as extremely attractive are seen mythological methods of influence (control, manipulation the person) which use archetypal stories, symbols, allegories, referring to the primary sense of the unity of the world, experienced by every person in childhood. Myth as a unified representation of the society on the man and the world of ancient has not survived, but the method of constructing a world order in mythological consciousness as a model of perception, experience and characterization of events lays at the base of consciousness till now and is especially clearly manifested in the production of mass representations.

We can claim that the mythologization of the Indigo children topic is a reflection of the general ideas of modern 
researchers, which in the sensory-specific form state the incipient awareness of the crisis occurred in the system of values, goals, and links on education and socialization of the younger generations in a society of a prefigurative culture.

In general, the current state of social and human knowledge on the issue of Indigo children can be characterized as inconsistent and largely mythologized due of the merely beginning of the path to its research, and because of the ontological and epistemological conflict in its very essence.

\section{Discussion}

In contemporary society we can state the rapid spread of intergenerational experience translation prefigurative culture. All this allows us to pose the question of the new nonclassical era of childhood onset, which has its special features. Recent positive changes in the world of childhood include agility in a fast changing society, easiness in technical facilities orientation, the expansion of the material world of the child, the convergence of the position of adult-child. Negative changes can be considered as follows: instability and increased susceptibility of consciousness and behavior of the child, increased conflict in the child-adult world relationship, extinction of the Pretend Play traditions, a significant children's folklore heritage loss, excessive immersion in the virtual world.

Adult world is a major factor responsible for the childhood socialization, in transmission of accumulated in history knowledge and experience of life. Reshuffle in the social status of these worlds in a single society is the path to the cultural primitivism. This situation is described, for example, in the Lord of the Flies (Golding, 2014). The novel describes a situation of children society primitivization on a small and forgotten island in the ocean. Left without the impact of culture socializing adults, quickly arrange children's team, based on quite simple and even primitive in terms of the modern culture instincts, finding themselves in the form of a small but brutal dictatorship of the "strong" teenagers.

Some examples of educational community involvement the into the idea of liberal education for children and youth, when they are commited without showing children the importance of moral responsibility initial foundation awareness, appear like hemming the life-giving roots of the human spiritual values. This is merely a step towards the younger generations provocation to break the bond of their socio-cultural relations and agressively confront the adult world, the world diferent from their. It is easy to predict that all this may lead to an increase in social chaos and turmoil.

\section{Conclusion}

The topic of intergenerational relations prefigurative culture is important not only for pedagogy it has a systemic nature. For example, it is extremely topical in the political sphere, when the young generation go to the city squares and into the political arena with the aim of changing the whole world (both the World of Adults and the World of Children) in the forms with a pronounced youth-centric and often extreme nature. It is necessary to analyze these political, economic and cultural youth forms not only in terms of their content, but also in terms of the bases of their organization and formulated methods of interests and goals achieving. The worldview and values, cultivated in the younger generation, have their major part to play here. The history proved the key to the future of humanity to be is in its worldview, ideology as a system of ideas and key notions.

\section{Acknowledgements}

This work is an output of a research project implemented as part of the Basic Research Program at the National Research University Higher School of Economics (HSE).

\section{References}

Abramenkova, V. V. (2009). Social Psychology of Childhood: The Development of Relations in Child Subculture. Moscow: Publishing MPSI.

Alexander, B. K., Anderson, G. L., \& Gallegos, B. P. (Eds.). (2004). Performative Theories in Education: Power, Pedagogy, and the Politics of Identity. London: Lawrence Erlbaum Associates.

Benoist, de. A. (2009). Against liberalism. Russian Idea, 1, 68-87.

Carroll, L., \& Tober, J. (1999). The Indigo Children: The New Kids Have Arrived. Carlsbad, Calif.: Hay House.

Delors, J. (1996). Learning: The Treasure Within. Paris: UNESCO.

Elkonin, B. D. (1992). The crisis of childhood and grounds design forms of child development. Questions of Psychology, 3-4, 7-13.

Elkonin, D. B. (1978). Psychology of the Game. Moscow: Pedagogy. 
Golding, W. (2014). Lord of the Flies. Moscow: AST.

Goralik, L. (2008). The Little Prince and High Expectations. New Maturity in Modern Society, 8. Retrieved from http://linorgoralik.com/little_prince.htm

Kudryavtsev, V. T. (2001). Studies of child development at the turn of the century. Questions of Psychology, 2, $3-21$.

McLaren, P. (1993). Schooling as a Ritual Performance. Towards a Political Economy of Educational Symbols and Gestures. London and New York: Routledge.

Mead, M. (1988). Culture and the World of Childhood-Selected Works. Moscow: Nauka.

Panitsidou, E., \& Papastamatis, A. (2009). European Lifelong Learning Educational Policy in the Light of the "Lisbon Agenda": The Greek Case. Review of European Studies, 1(1), 2-8. http://dx.doi.org/10.5539/res.v1n1p2

Papanis, E., Giavrimis, P., \& Papani, E. -M. (2010). The contribution of the Internet into learning. Review of European Studies, 2(1), 54-60. http://dx.doi.org/10.5539/res.v2n1p54

Piaget, J. (1968). The Moral Judgement of the Child. London: Routledge and Kegan Paul.

Savenkov, A. (2009). "Indigo children". Genealogy of a dangerous myth. Modern pre-school education. Theory and Practice, 2, 12-19.

Shalaev, V. P. (2013). Current Synergetics: Man and Society in the Era of Global Transformations. Yoshkar-Ola: Volga State University of Technology.

Shalaeva, S. L. (2009). The adult world and the world of childhood in the challenges of a global society. Regional Studies, 2, 258-262.

Shalaeva, S. L. (2009b). Transformation of childhood in a globalizing world: The synergistic aspect. In V.V.Vasilkova (Ed.), The Synergetic Paradigm. Social Synergetics (pp. 517-528). Moscow: Progress-Tradition.

Valkanos, E., Giossi, S., \& Anastasiadou S. (2010). Certified Adult Educators' Attitudes towards Continuing Education. Review of European Studies, 2(1), 61-71. http://dx.doi.org/10.5539/res.v2n1p61

Vygotsky, L. S. (1984). Infancy. L. S. Vygotsky. Collected Works, 4, 244-268.

Willis, P. (1999). Labour power, culture and the cultural commodity. In M. Castlls, R. Flecha, P. Freire, H. Giroux, D. Macedo, \& P. Willis (Eds.), Critical Education in the New Informative Age. Oxford: Rowman and Littlefield.

Wulf, Ch. (2001). Einführung in die Anthropologie der Erziehung. Weinheim und Basel: Beltz Verlag.

Wulf, Ch. et al. (2010). Ritual and Identity: The Staging and Performing of Rituals in the Lives of Young People. London: the Tufnell Press.

\section{Copyrights}

Copyright for this article is retained by the author(s), with first publication rights granted to the journal.

This is an open-access article distributed under the terms and conditions of the Creative Commons Attribution license (http://creativecommons.org/licenses/by/3.0/). 